\title{
The institutional effect on leisure time and competitive sports at higher education colleges and universities in the Carpathian Basin
}

Authors' Contribution: A Study Design B Data Collection

C Statistical Analysis D Data Interpretation E Manuscript Preparation F Literature Search G Funds Collection

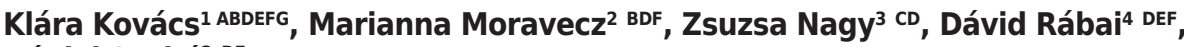 \\ Dániel Szabó ${ }^{2}$ DE \\ ${ }^{1}$ Institute of Education and Cultural Studies, University of Debrecen, Hungary \\ ${ }^{2}$ Institute of Physical Education, University of Nyíregyháza, Hungary \\ ${ }^{3}$ Educational and Cultural Doctoral Programme, University of Debrecen, Hungary \\ ${ }^{4}$ Department of Child Education, University of Debrecen, Hungary
}

abstract

Background: The objective of our study is to reveal the resources within colleges and universities that may influence the leisure-time and competitive sports done in the respective institutions. For the theoretical background of our research, the models examining the institutional effects were used. Strange [1] arranged the models into four categories.

Material and methods:

Results: In accordance with our findings, the institutions were arranged into four categories: Competitive-sport oriented institutions, institutions using sport as a means of creating and reinforcing the community, institutions that minimize physical culture, and institutions that only deal with the required physical education classes.

Conclusions: At the section of our research related to leisure-time sport, we found that substantial financial resources, adequate infrastructural conditions, facilities, and a positive attitude of the leaders of the institution are very important. In connection with competitive sports, we may conclude that sport is highly prestigious, and competitive sport is used effectively to attract students to the university.

Key words: leisure sport activity, competitive sport, higher education, students, institutional effect.

\section{article details}

Article statistics: Word count: 6,098; Tables: 0; Figures: 2; References: 18

Received: June 2020; Accepted: August 2020; Published: November 2020

Full-text PDF: http://www.balticsportscience.com

Copyright

Indexation:

(c) Gdansk University of Physical Education and Sport, Poland

Celdes, Clarivate Analytics Emerging Sources Citation Index (ESCI), CNKI Scholar (China National Knowledge Infrastructure), CNPIEC, De Gruyter - IBR (International Bibliography of Reviews of Scholarly Literature in the Humanities and Social Sciences), De Gruyter - IBZ (International Bibliography of Periodical Literature in the Humanities and Social Sciences), DOAJ, EBSCO - Central \& Eastern European Academic Source, EBSCO - SPORTDiscus, EBSCO Discovery Service, Google Scholar, Index Copernicus, J-Gate, Naviga (Softweco, Primo Central (ExLibris), ProQuest - Family Health, ProQuest - Health \& Medical Complete, ProQuest - Illustrata: Health Sciences, ProQuest - Nursing \& Allied Health Source, Summon (Serials Solutions/ProQuest, TDOne (TDNet), Ulrich's Periodicals Directory/ulrichsweb, WorldCat (OCLC)

Funding: This research is project no. 123847, supported from National Research, Development and Innovation, financed from K_17 application program, and was published with the support of János Bolyai Research Scholarship (2016-2019).

Conflict of interests: Corresponding author: Open Access License:
Dr Klara Kovacs, 4032 Debrecen, Egyetem sqr. 1; Tel.: +36203877968; e-mail: kovacs.klara@arts.unideb.hu.

This is an open access article distributed under the terms of the Creative Commons Attribution-Non-Commercial-NoDerivatives 4.0 International (https://creativecommons.org/licenses/by-nc-nd/4.0/), which permits use, distribution and reproduction in any medium, provided the original work is properly cited, the use is non-commercial and is otherwise in compliance with the license. 


\section{INTRODUCTION}

The institutional factors are the ones that influence changes in students during the years of their advanced studies. Such factors include values, behaviors, attitudes, or even efficiency [2-5]. We regard the students' willingness to do sport a change or progress. In that respect, we wished to identify the institutional factors that tend to influence their sport activities. The theoretical models of institutional effects on the students' change/progress serve as a foundation of our research. The theoretical models suggest that the students' change is rooted in interpersonal interactions and environmental factors. The change is, however, not necessarily positive, nor is it always progress, individual development. The institutional factors consist of a number of components: some of these depend on the students (gender, ethnicity, socio-cultural background, differences in learning efficiency) [6], but they also belong to structural and organizational characteristics (the size of the institution, mechanisms of selection, curricula) and to environmental conditions (the cultural, social and political climate created by the faculties or students) [7]. In our research, we target the institutional resources that may influence the leisure-time and competitive sports going on at the institution concerned, the students' attitudes to sport, the organizational characteristics of sports, goals, values, personal characteristics and infrastructural conditions. We intend to reveal and identify these indicators of the institutional effects and see how they work in the leisure-time and competitive sport of some higher education institutions in the Carpathian Basin.

The type, characteristics and mission of the institution together constitute an atmosphere that differentiates one institution from another. It appears in the classrooms, student organization and interactions [8]. This approach emphasizes the institution's responsibility for creating environmental conditions that benefit the students and serve the progress of the institution [9].

Out of the models studying institutional effects, we chose for our research the ones that concentrate on an individual's behavior through their personality characteristics. Strange [1] arranged these models into four categories, and these categories fully match the critical elements necessary for the examination of the campus environment [9]:

1. Physical models (e. g. infrastructural features);

2. The models concentrating on human resources (personal factors: teaching staff, students etc.);

3. The models of organizational environment (organizational culture and objectives);

4. The models of the constructed environment (the participants' perceptions and opinions).

1) Physical models: these theories and models concentrate on the effects of external physical environment, which may determine certain behavior patterns and raise an opportunity for various activities (e.g. gyms, parks, equipment, tracks, halls required for sport). Here we include the infrastructure important from the viewpoint of our subject. The socio-economic models dealing with health protection examine the personal, social, institutional and physical-environmental factors, such as access to sports facilities that influence an individual's behavior. In these models, it is emphasized that multi-dimensional analyses are required to understand and change individual behavior patterns in connection with health protection. Environmental factors, such as access to sports facilities, may serve as a catalyst in developing the health-conscious behavior of individuals [10-12].

Earlier research findings indicate that the more supportive the physical environment in a community is, the more accessible and affordable, the more civilized and safer the sports facilities (appropriate sidewalks, parks for walking and cycling, jogging, spaces for sports) are, the more likely it is that local people will be active in sports $[10,13,14]$. It was found that the good sidewalks had the most powerful influence on local people's physical activity [13]. Other surveys have revealed that, although access to sports facilities does not have 
a considerable direct influence on the sports activities of adolescents, it does have an indirect positive effect on their willingness to do sports [11].

A look at the sport life of college and university students shows that twice as many students are active in sports outside the campus than within. The sports facilities of the campus have been found to be particularly unattractive for female students. Pfau and Domonkos [15] summarized the opinions of sports managers and found that two thirds of them are dissatisfied with the sports facilities of their respective campuses Furthermore, three quarters are dissatisfied with the existing financial resources and find some progress and development in these fields indispensable.

2) The models concentrating on human resources: these theories examine the influencing power of human environment on the participants' characteristics (e.g. socio-cultural background, values and attitudes). In this way, the interactions and interrelations between various members of communities of socialization (teachers, staff members and students), how they influence each other, and how they share their values, attitudes and interests with one another. The question we intend to address is how the sport activities of various members of the university (especially leading faculty members and teachers) influence the students' attitude to sports, and how the students' sport activities influence the sport activities of their peers, fellow students.

Pfau and Domonkos [15] included 18 Hungarian institutions of higher education in their survey and highlighted an important problem. One of the reasons for the difficulties in organizing leisure sport at some universities is that the leaders of the institution are not supportive of that. For the university leaders responsible for sport, PE teachers, trainers and coaches, it is an important motivation when their work is respected and acknowledged. The authors also point out that among the students, the reasons why sport is not very attractive include sheer laziness and lack of motivation. For students, the most important motivation is the role model of the teacher and, in addition to cheap or free sport facilities that appear to be a powerful motivating force on campus. On the other hand, the example of friends and peers motivates students to do sports outside the campus [16].

In one of our earlier research projects, we examined the effects of social background variables on the attitudes to the avoidance of health risks among students in the Carpathian Basin. The examined variables included the health preservation patterns characteristic of institution or faculty as a meso-level factor, the inter- and intragenerational embeddedness of the students and their membership in voluntary organizations and NGOs [7]. Our findings underpinned the outstanding importance of the campus culture and atmosphere in the students' health-conscious behavior. In a health-conscious campus society, a student has twice as high a chance to avoid harmful habits. On the other hand, powerful and multiplex embeddedness in the society of peers considerably increases the chances or hazardous behaviors. Voluntary work and civilian activity tends to drive the students' behavior in the positive direction.

3. The models of organizational environment deal with the system of institutional objectives, values and activities that constitute the institution's structure and design. The system includes the institutional-organizational characteristics that directly influence operation, the message the institution sends out about itself, and the efficiency of the work at an organizational level.

Characteristics:

- structural framework (how the organization is built up in order to achieve its objectives); 
- concentration on the framework of human resources (motivation, needs, commitment, training, employment and socialization of the individuals working at the organization);

- political framework (it helps the leaders understand the methods and processes with the help of which they are able to build up a common vision that mobilizes people, convinces other people and determines the resources necessary for the success);

- the symbolic framework (mission, vision and values that the institution hands down to the new generations at rituals and celebrations, and supports activities, practices and policies that are otherwise typically ignored) [17].

Kezar [17] argues that, in order to understand how the organization of an institution is able to follow the continual social changes, the institutional culture and signal transfer are to be examined. From the aspect of our subject matter, we look at campus culture as long lasting patterns of norms, values, expectations and beliefs that all shape the behaviors of individuals and groups at the colleges and universities and that provide a framework for the interpretation of events and activities going on within and outside the campus. There are three levels of campus culture: products, values and basic assumptions/beliefs. The products refer to the symbolic aspects of the campus culture; this is the tangible evidence of the work of culture. These products include, among others, the inauguration procedures of first-year students, or the community traditions, standards and expectations. Such products are characteristic idioms used on campus, anecdotes handed down from generation to generation. The values are the theories, ideas accepted and relayed on by the campus. Diversity, intellectual liberty as well as critical thinking as values are usually explicitly present in the sense of institution's mission. The basic assumptions and beliefs are not as explicitly present in the life of institutions as values, but they are also able to shape and influence the way of thinking, theories, perceptions and emotions at the campus to the same extent [8].

In the case of a higher education institution, an examination of the sports concept may provide the framework in which we are able to learn about the real and symbolic role of sport in the life of the institutions concerned. The sport concept includes the tasks and solutions that help the students in developing a health-conscious way of life and, as part of it, life-long socialization in sports. The concept of institutional sports may be divided into three sub-categories: the organization of physical education (classes, tasks and commitments), providing for the conditions of both leisure time and competitive sport events and programs [16]. Pfau's [18] nationwide survey revealed that the tasks of organizing leisure-time sport almost exclusively belong the PE teachers. At Eötvös University in Budapest, it is the responsibility of BEAC, their own sports club. As for competitive sports, students' self-governments also appear as organizers in addition to $\mathrm{PE}$ teachers. As free time sports activities are able to mobilize the largest numbers of students, it is clear that the greatest emphasis is to be placed on these programs.

It is an important issue to chart the role of sport in the mission statement, life, history, campus culture of an institution, on what values the organization of sports rests, what programs and events are organized, and what systems are operated and how.

4. The models of constructed environment: earlier Pascarella and Terenzini [2] referred to these models as perceptual models, emphasizing the social-psychological and culturalanthropological approaches used in these models. Strange's [1] classification also refers to the perceptions, values and experience when analyzing the components of the institutions. For our research, we sought the opinion of the students regarding the sports facilities and possibilities at the institution. It is important, because an earlier research found that $87 \%$ of the sports managers were dissatisfied with the way colleges and universities motivate students to do sports [15]. On the other hand, 89\% found the leisure-time sports 
facilities and opportunities acceptable or good [16]. Since in our qualitative survey we approached the issue from the viewpoint of the institutions and did not ask the students' opinion, the inventory research going on at present will be suitable for learning about the students' views. We may learn from the research that serves as a basis for our study how to obtain information from the students about their habits of doing sports, if any, and what their expectations are in that respect in connection with their host institutions. We also need to know how to process the obtained data. Furthermore, we may learn how our respondents see the attitude of students to sports, so we may be introduced to the students' perceptions as well.

\section{MATERIAL AND METHODS}

In the framework of our research, we conducted 15 structured interviews in 14 institutions in Hungary, Romania, Ukraine, Slovakia and Serbia. The interviews took place in the following institutions: the University of Debrecen (three people), the University of Nyíregyháza, "Ferenc Kölcsey" Teacher Training Faculty of the Protestant Theological University of Debrecen (Hungary), The Christian University of the Partium (Oradea, Romania), the State University of Oradea (Romania), Babes-Bolyai University of Kolozsvár (Cluj, Romania), the branches of BBU at Kézdivásárhely (Târgu Secuiesc, Romania) and Sepsiszentgyörgy (Sfântu Gheorghe, Romania) (the same individual), the State University of Mukachevo (Ukraine), the State University of Uzhhorod (Ukraine), "Ferenc Rákóczi II" Subcarpathian Hungarian College (Berehovo, Ukraine), "Sapientia" Hungarian University of Transylvania, Marosvásárhely (Târgu Mures, Romania), the University of Novi Sad Hungarian Language Teacher Training Faculty (Subotica, Serbia), “János Selye” University (Komarno, Slovakia) (one person each). The interviews were conducted in Hungarian, English or Ukrainian. The surveyed institutions were arranged into four categories, according to their attitude to sport and the role of sport and physical education at the college or university: competitive sport-biased institutions, the ones building a community through sport, PE-biased, and institutions minimizing physical culture. The interview questions related to the following subjects: social and institutional factors (institutional background; rules and regulations in connection with sports; sport among students; events, programs; the students' health and fitness status; tightening the rules related to required $\mathrm{PE}$ classes, ecological factors, infrastructure, equipment, financial factors (costs, resources, scholarships, incomes); personnel issues (PE teachers, lecturers, part times teachers, their experience, tasks, expectations), future plans.

\section{RESULTS}

Out of the institutions involved in our research, leisure time sports events and programs are implemented at the competition sport-biased colleges, the colleges building a community through sport and the PE-biased ones. In general, every single one of them intends to popularize sport and to make students aware of the importance of physical activity and building a community. The difference between the individual institutions primarily lies in the authorities' attitude, financial resources, and infrastructural equipment. Leisure time sport is not present at all at the institutions minimizing physical culture; they restrict their efforts to providing the PE classes required by the law and not more.

It is possible to identify some points of difference between the institutions supporting leisure-time sports. While the universities supporting competitive sport also devote considerable resources to organizing free time sports events, competitive sport is more important for them than for the other institutions. In their case, leisure-time sport is a forum and opportunity to select competitive athletes. The institutions that wish to build up a community with the help of sports, organize sports events primarily to unite students 
into communities. These institutions also attribute importance to making students aware of the importance of lifelong health consciousness. PE-biased institutions appear to pay less attention to the organization of sport events and programs. Their main profile is to provide the required minimum of physical education classes. Clubs and associations that serve as a framework of students' leisure sport usually stem from those PE classes.

An examination of the organizational background shows that the institutions that have a special organizational unit for sports are able to generate outstanding sport life, including events and public programs. The University of Debrecen has a Department of Coordination; some have a Sport Office or Department of Physical Education. At the competition sportand physical education-biased as well as the community building institutions the purpose of these programs is making students love physical exercises. The programs will, however, only function effectively and achieve their goals when 1) students' opinions, ideas and expectations are taken into consideration, and 2) the participants also receive some external motivation. Our interviewee at the Protestant Theological University of Debrecen reported that major sports events (whole night football), which had required considerable efforts to organize, were finally cancelled for lack of interest. The main reason for that is probably that physical education and sport have not played an important role in the life of theologians so far. After the infant teacher training college had been integrated into the university, it was a new experience for the latter that the ideas of such programs emerged. The same interviewee accounted that the "compulsory" nature of PE classes might scare some students away. At the College of Berehove, however, it was evident that the required classes provided a regular weekly opportunity to do sport for many students who had never done it before. Some of these students who had never had an opportunity to have any regular, organized physical education were now offered a chance of doing exercises on a weekly basis, getting acquainted with new types of sport, gathering positive experience and making life-long friendships. Therefore, it is not surprising that out of the nine elective courses the six sport club-courses are highly popular. At the competitive sport-biased colleges and universities sports events and programs also serve as an opportunity to select capable athletes and build teams.

The university regularly organizes athletic competitions, football and volleyball matches, table tennis and chess competitions on the campus. The purpose of these events is to make sports and physical exercises more popular and provide a forum for the selection of the most talented students. The selected students are organized into teams, and they represent the university at national events... The programs are organized exclusively by the Department of Physical Education, with the occasional help of the Students' selfgovernment (Competitive sport-biased institution).

It is necessary to emphasize the role of the students' self-government in these programs. It is now clear how important their attitude and opinion of sport is, especially at the institutions minimizing physical culture. At these places, physical culture and education are restricted to the required PE classes, taking place among minimal infrastructural conditions, sometimes with the guidance of one single PE teacher. If the students' selfgovernment is detached from these activities and attributes no significance to instigating and operating some sport activity at their respective institution, any initiative in that respect will be seriously hampered.

In leisure sport, not only the institutional factors are important, but also the infrastructural conditions, i.e. sports facilities. Good sports facilities are indispensable for college and university students who wish to pursue some sport in their free time. The different types of institutions we discussed earlier pay different amounts of attention to the issue. At the competitive sport-biased colleges and universities, developing leisure-time sport is also an organic part of their mission. They survey and analyze the students' needs 
and expectations, and then they implement infrastructural investment and development projects based upon the results of their surveys. The institutions that use sport as a means of building a community also make efforts to create the necessary infrastructure and facilities for free time sport at their campuses, but their infrastructure and facilities are usually a lot more modest than those of the colleges and universities that belong to the previous category. Consequently, they are unable to sustain a sport life similar to that of the colleges above. Sports and PE facilities are the most modest at the PEbiased institutions and those that tend to minimize physical culture. Leisure-time sport suffers a lot at those institutions. These institutions rarely possess more than the minimal infrastructure required for the weekly PE lessons.

After listing the above differences, we proceed on to concentrate on the basic, most important similarities between the colleges and universities. At the examined institutions, we found the most significant common points in the role of teachers. In the practice of the competitive sport-biased institutions, several teachers themselves used to be competitive athletes at a younger age and also work as coaches. In these colleges and universities, it is expected that teachers should represent the institution at leisure sports events and programs.

What we expect from them is that they should represent the University of ... in a way that is worthy of the institution's image and reputation, and demonstrates our commitment to physical education (Competitive sport-biased institution).

At the institutions that use sport as a community-developing agent, the use of interpersonal connections and interaction between teachers and students is of decisive importance. As part of this interaction, the teacher should learn about the expectations, requirements, problems and ideas of their students, and it is only possible through personal conversations during classes.

...human relations are closer, since at physical education classes the desk and the table are not present between the students and the teachers, so the connections are quite direct, we are close to each other, and it determines all our activities (Community building institution) .

At the PE-biased colleges and universities, the key role of the physical education teachers is to promote the goals of sports programs at which students of various subjects and courses may develop into a real community. To attain that end, it is necessary for the teachers to be in direct connection with their students. In some cases, the teacher may make the attendance in $\mathrm{PE}$ classes compulsory, and it may either be bound to the credit system (e. g. Christian University of the Partium), or a criteria requirement (University of Debrecen, University of Nyíregyháza, János Selye University, Ferenc Rákóczi II. College, the State University of Mukachevo), and in the long run it may help students to recognize the importance of physical exercise and, ultimately, to lead them to a more health-conscious way of life.

...I made class attendance compulsory, and the students found it strange at the beginning, but in the end they said thanks and claimed that it was good that it had been made compulsory, otherwise they would not have come to the classes, but in this way they had a fantastic experience. It is compulsory in the first year, but it is not compulsory later, they come without any obligation (PE-biased institution).

At the institutions that minimize physical culture, only PE teachers, with their persistence and enthusiasm, are able to sustain the love of exercise in the students.

The next component we examined is the sport concept of the institutions. The competition sport-biased colleges and universities usually have an elaborate and complex institutional 
sports concept. It includes the coordination of their annual plans related to sports events and programs. A sport concept is usually not that explicitly present in the institutional culture of the other college and university types, but a lot of them have devoted PE teachers whose commitment shows that their primary objective is to make students love physical exercise and sport. The sport concept of the University of Debrecen is unique in the whole country, even among the competition sport-biased institutions; it is so complex and professional. The students' attention is drawn to the importance of sport on every possible forum popular with young people.

...where necessary, we hand out flyers, we send messages through Neptun [the standard student administration network in Hungarian higher education], we are active on Facebook, we put up posters, and we also talk to students personally (Competitive sport-biased institution).

In order to manage the complex sport activities going on at the University of Debrecen, a Coordination Institute of Sport Affairs was established in 2015. Sport offices were established at the major Hungarian universities through the applications of the Hungarian Sport Association of Colleges and Universities. That is how the offices were established at the Universities of Debrecen and Nyíregyháza, where the offices work in cooperation with the students' self-governments. The major difference between the two universities is that while in Debrecen the Coordination Institute of Sport Affairs is an important unit in the organization, in Nyíregyháza the survival and operation of the office depends on the funds won at successful applications and bids. Similar is the case at the Hungarian Faculty of the University of Novi Sad.

At competitive sport-biased and PE-biased as well as community forming institutions it is a common and important aspect of organizing principle to offer the widest possible choice of events to students in the most attractive way. One of the major goals is to involve students in community programs and to raise their awareness in terms of healthy life.

I believe that a university sport office is simply unable to provide a service more important than building and shaping a community through sport (Competitive sport-biased institution).

At the institutions that tend to minimize physical culture there are hardly any leisure sport programs, as there is no infrastructure, institutional background and commitment. The organization and implementation of PE classes is exclusively the responsibility of PE teachers.

It is not surprising that the highest level of organization is found at the competitive sportbiased institutions. There, competitive sport is incorporated into the daily life of the college, its identity and sense of mission, and has a double function. On the one hand, it promotes the importance of sport and competitive athletes for the institution among the students and the external world; on the other hand, it suggests to the actual students that competitive athletes are acknowledged and supported; every opportunity is created for them to coordinate their studies and sports career. In this way, they demonstrate that pursuing studies and competitive sport simultaneously is possible. To achieve that goal, the institutions operate mentor- and scholarship programs. Where they do not have financial resources, they popularize competitive athletes by granting them awards and organizing meetings and other events. There is a serious recruitment work going on at PE classes and sport events to find talented people who will compete in the colors of the university, thus improving the prestige of their host institution.

The University of Debrecen is one of the competitive sport-biased institutions. They operate a sports club (DEAC) of their own for their own students and competitive athletes, 
making the university very attractive to those young people who wish to pursue some sport and do not want to give up their advanced studies. The university has several first- and second-league teams in different sports, and the majority of the team members are the students of the university, which has more than 1,000 registered athletes. They play in football, basketball, volleyball, ice hockey, and futsal teams and do individual sports. Our interviewee pointed out that these athletes were at the same time full-time students of the university: The real beauty and result of this situation is that these students are amateurs, do not receive a professional wage or other benefits, but they do it simultaneously with working or, more frequently, with studying (Competitive sport-biased institution).

Out of the examined foreign institutions, the Universities of Mukachevo and Uzhhorod appear to have outstanding sport- and competitive sport life. At both universities, they organize sports events and programs, and make efforts to enter their various teams for national, sometimes international competitions. Our interviewees at both universities point out that the sustenance and development of competitive sport at their respective institutions largely depend on the attitude of the university's authorities and added that the university leaders do their best to support competitive sport, as outstanding results improve the prestige of the institution. The University of Uzhhorod, for instance, organizes 60 competitions a year, which are open to the students, staff and employees.

The institutions that use sport for community building and those that restrict sport to physical education classes also have sports teams, even departments/sections within their associations, for instance at the University of Nyíregyháza. At these colleges and universities, however, financial restraints do not allow high standards of competitions. State subsidies may improve the situation. At national university tournaments, these institutions also enter their volleyball, basketball and handball teams, but for the lack of financial resources, they are unable to achieve considerable successes at that level. A sport club is the organization that is able to coordinate sports activities. We are anxious to find a club chairperson who is able to find financial support for the club. That would be a springboard for successes at a higher level. We would have students ready to compete, but we are unable to finance them (PE-biased institution). The College in Berehove also has several sport teams, but they are in the same situation as those at the University of Nyíregyháza, which belongs to the same category. They enter for various cups and tournaments, and they are only surpassed by the athletes of the competition sport-biased institutions, as these have a better financial situation.

At colleges and universities that minimize physical culture, competition sport at the institutional level is not present at all. There are, however, competitive athletes in the ranks of their students, and colleges make efforts to help them (individual curriculum, excusing from attendance at some classes). It is a positive phenomenon that institutions that do not deal with competitive sport at all provide opportunities to these outstanding athletes: They are exempted from the attendance at $50 \%$ of the classes. At the examinations, they may be offered dates different from the exam dates of the rest of the students (Physical culture minimizing institution). Similar is the case with PE-biased institutions. They tend to have a higher number of outstanding athletes, but the institutions, similarly to those that minimize physical culture, do not have competitive sport activities, but they do have students who are outstanding athletes. These institutions offer similar benefits to the students: Prominent athletes receive extra benefits such as individual curriculum, and our teachers help the students by offering them consulting and communication through Skype. It is particularly important when the students are abroad in training camps or competitions (PE-biased institution).

Professional environment and adequate facilities are especially important for competitive sports at universities that wish to host that kind of activity. At the categories we set up 
for our examinations, the competitive sport-biased universities are the ones that have above the average infrastructure, since competitive sport is a priority for them, and they attribute great significance to assist their athletes in preparing for the events under ideal circumstances. In general, these institutions carry out regular investments in their facilities in order to support competitive sport on their campuses. For the institutions that build their communities through sport, the support of competitive sport is not a priority, and they usually have fewer outstanding athletes as students, so their related facilities are more modest. They often lack the resources necessary to make major infrastructural investments. As they do have fewer outstanding athletes, there is no real need for such development. PE-biased and physical culture minimizing institutions often have very poor facilities, and when they have prominent athletes, they are usually unable to do quality training on campus.

\section{DISCUSSION}

Our study aims to explore the influence of different dimension of the institutional effect [2] on leisure and competitive sport in some Hungarian, Romanian, Ukrainian, Slovakian and Serbian higher education institutions. To answer research questions, four models of institutional effect were examined: physical models (e.g. infrastructural features), models concentrating on human resources (personal factors: teaching staff, students, etc.), models of organizational environment (organizational culture and objectives), and models of constructed environment [1].

The first figure illustrates the leisure-time sports events and programs at the different institution types. At the PE-biased colleges and universities, the constructed environment - adequate infrastructure and facilities - makes the organization and facilitation of sports events easier. It is closely related to the organization of physical education. Raising health awareness is of great importance in these colleges and universities. Efforts are made to meet the students' needs in terms of physical exercises, and the leaders of the institution take care that the students who are not competitive athletes may also participate in different competitions.

The number of sports events and programs is not very high at the college and universities that minimize physical culture, but there is an overlap between the standards of the constructed environment and leisure activities taking place on the campus. This may, however, be attributed to the community forming effects of sport, even though sport is not very intensive there.

The most significant overlap between free-time sport and competitive sport is found at the competitive sport-biased institutions. The colleges and universities differentiate between the two dimensions. They provide opportunities for both the established athletes and those who only do sport for recreation. In both cases, the environment is supportive, but especially powerfully so in the case of the competitive athletes (individual curriculum, sport scholarship). These students enjoy more freedom than the students who do not do sport at the same high level. The excellent facilities are also suitable for leisure sport, and the presence of such events is of key importance in forming the constructed environment. The colleges and universities using sport as a community building means are fairly similar to the competitive sport-biased ones, but while in the former the emphasis lies on competitive, elite sport, in the latter it is on free time and that is how they shape the atmosphere of the campus. The students are treated as a homogeneous community, where everybody has access to the sports facilities and programs. Competitive sport is treated as an event, where the students turn up as visitors and spectators. Competitive athletes are supported with sports scholarships. 

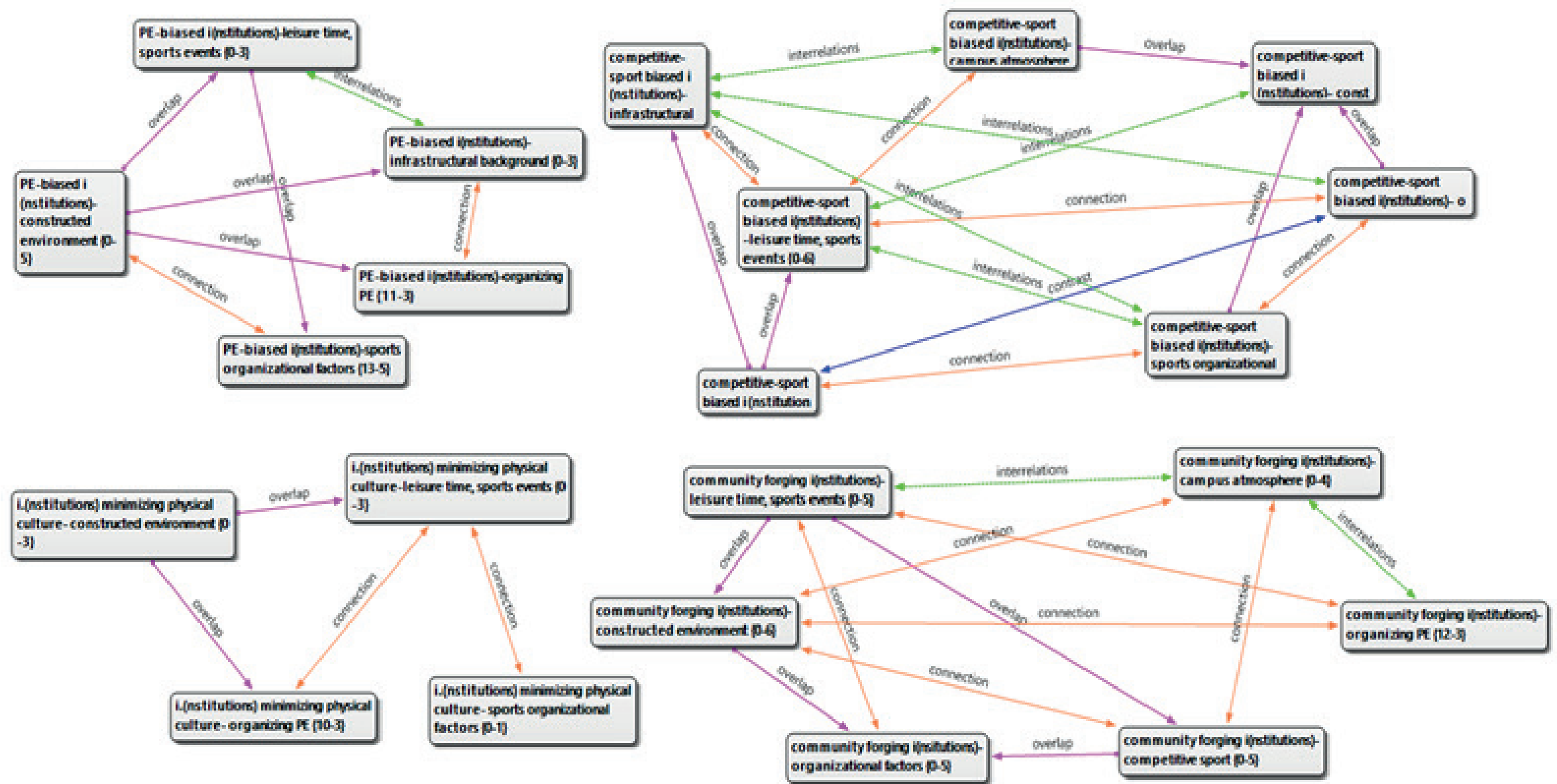


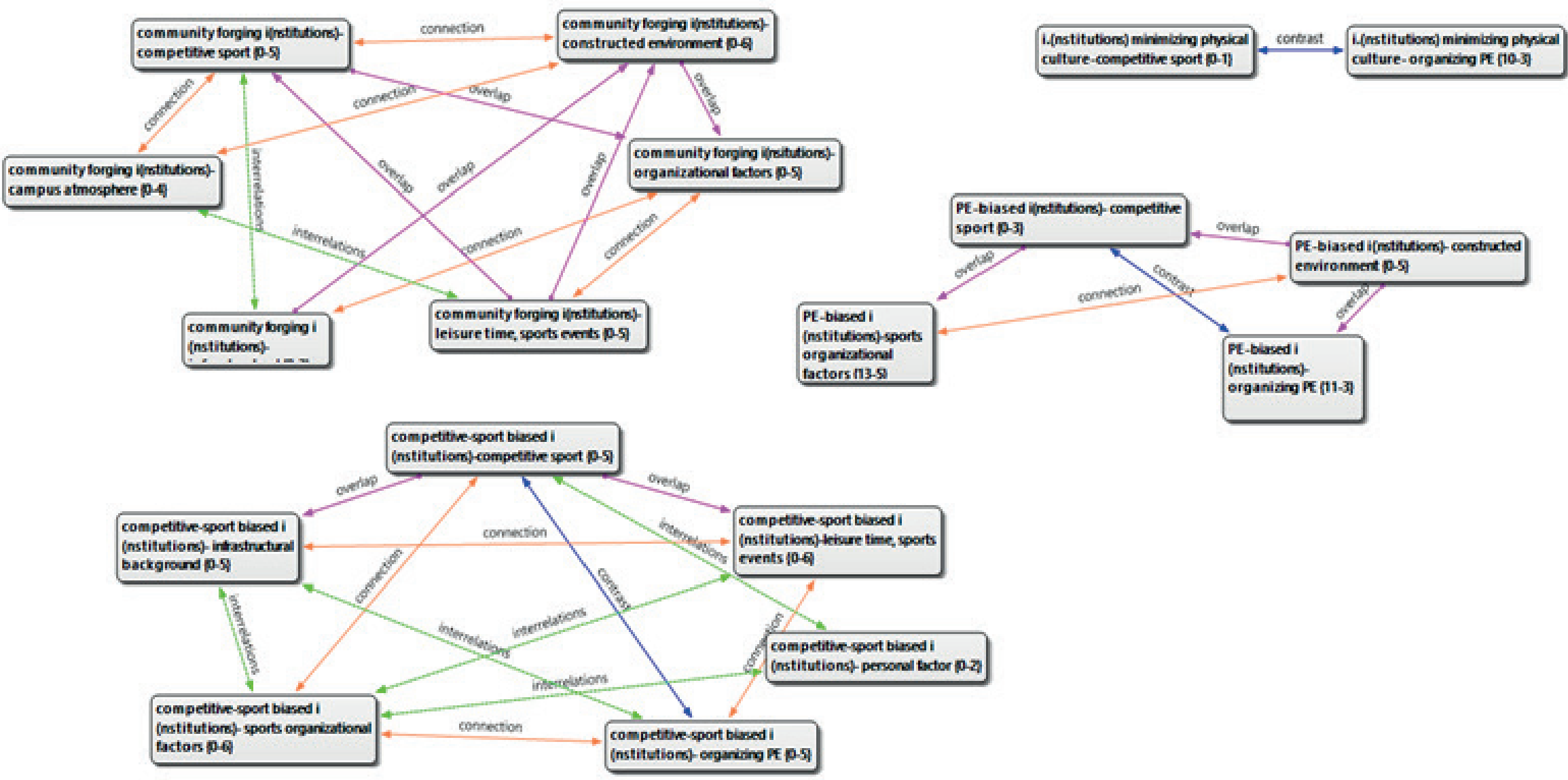


Figure 2 shows competitive sport going on at the institution types we surveyed. At the colleges and universities that use sport to build a community, there is a close interrelation between the infrastructural background and competitive sports. These institutions usually have excellent facilities (sports halls, gyms, tracks), and they are able to organize events and programs, and mobilizing the potential audience is also easier. These institutions make a good use of their facilities to meet the students' needs and to improve the campus atmosphere. The university, like a family, supports the sport activities of their competing students.

At the PE-biased colleges and universities, competitive sport is closely related to the constructed environment and the sport-organizational factors. "Mass sport" and the organization of the PE classes are given more attention than competitive sport. Competitive sport appears at the university when students who are already competitive athletes enroll.

At the institutions that minimize physical culture, competitive sport is not noteworthy. There are no competitive sport events and outstanding athletes there. They organize the required physical education classes, and that is the only organization they do in that respect.

At competitive sport-biased colleges and universities, students' sport activities are arranged around competitive sports events. These institutions use their infrastructure and facilities designed for competitive sport to involve students who are not elite athletes in sport activities. When students who are otherwise not competitive athletes are successfully involved in competitions that, in turn, reinforces the success of the university in national and international sport. Scholarships are offered to support the competitive athletes, and individual timetables make their studies and sport activities easier.

\section{CONCLUSIONS}

Our objective with our research was to reveal the various dimensions (physical, organizational, constructed environment and personal) of institutional effects on the sport life at various domestic and foreign institutions of higher education. Across the border, we primarily selected institutions with a high number of ethnic Hungarian students. Our main objective was to map the institutional effects on leisure and competitive sports at colleges and universities and how these effects influence the students' sport activities.

At the section of our research related to leisure sport we found that substantial financial resources, adequate infrastructural conditions, facilities, and a positive attitude of the leaders of the institution are very important, but the personal conditions and the personal example of the physical education teacher are indispensable in the process of students' sport-socialization. In some cases, the personal enthusiasm, commitment of the teachers may counterbalance meagre facilities and the lack of a concept. The work of devoted teachers may substantially contribute to the implementation of the common goals of the institution concerned, to direct students towards sport and the joy of physical exercises. In this way, the devoted teachers are instrumental in shaping and developing their own communities.

In connection with competitive sports, we may conclude that out of all the institutions concerned, the competitive sport-biased colleges and universities-not surprisingly-stand out in terms of the intensity of campus sport life. At these institutions, sport has high prestige, and competitive sport is used effectively to attract students to the college or university. Our analyses revealed that both the (positive) attitude of the leaders of the university and the commitment of the PE teachers are required to sustain and operate a complex sport-logistic system. At the other institution type, it is those that use sport as a means of building a community that tend to have competitive sport activities on campus. 
These institutions, however, often lack the necessary financial resources, or the leaders of the institution are not very supportive. For these reasons, these colleges and universities are unable to achieve the same standards as those with a powerful competitive sport bias. On the other hand, when these institutions have the appropriate facilities, they tend to make efforts to utilize them for both free time and competitive sport events and to mobilize students to participate.

\section{REFERENCES}

[1] Strange CC. Dynamics of campus environments. In: Komives SR, Woodard DB Jr, editors. Student Services: A Handbook for the Profession. San Francisco: Jossey-Bass; 2003, 297-316.

[2] Pascarella ET, Terenzini PT. How college affects students? 2nd edition. San Francisco: Jossey-Bass; 2005.

[3] Muller A. A szabadidos tevekenysegek kinalati elemeinek vizsgalata az egeszsegtudatos magatartas kialakitasaban [Examining the supply elements of leisure activities in the development of health-conscious behavior]. Habilitation thesis. Debrecen: University of Debrecen; 2009. Hungarian.

[4] Balatoni I, Varga Szépné H, Müller A, Kovács S, Kosztin N, Csernoch L. Sporting habits of university students in Hungary. Balt J Health Phys Act. 2019;1(2). https://doi.org/10.29359/BJHPA.2019.Suppl.2.05

[5] Buhas S. Sports and Physical Education - Forms of Socialization. GeoSport for Society. 2015;3(2):53-60.

[6] Nowak-Zaleska A. Candidates for the First Year of Studies at the University Level Institution of Physical Education and Their Physical Activity. Balto J Health Phys Act. 2011;3(3). https://doi.org/10.2478/v10131-011-0019-z

[7] Pusztai G, Kovács KE, Kovács K, Nagy EB. The effect of campus environment on students' health behaviour in four Central European countries. J Soc Res Policy. 2017;8(1):125-138.

[8] Renn KA \& Patton LD. Institutional identity and campus culture. In: Schuh JH, Jones SR, Torres V, editors. Student Services: A Handbook for the Profession. 6th edition. San Francisco: Jossey-Bass; 2017, 58-72.

[9] Museus SD. Environmental theories. In: Schuh JH, Jones SR, Torres V editors. Student Services: A Handbook for the Profession. 6th edition. San Francisco: Jossey-Bass; 2017, 236-251.

[10] Pan SY, Cameron C, DesMeules M, Morrison H, Craig CL, Jiang X. Individual, social, environmental, and physical environmental correlates with physical activity among Canadians: A cross-sectional study. BMC Public Health. 2009; 9(1):21. https://doi.org/10.1186/1471-2458-9-21

[11] Prins RG, van Empelen P, te Velde SJ, et al. Availability of sports facilities as moderator of the intention - sports participation relationship among adolescents. Health Educ Res. 2010;25(3):489-497. https://doi.org/10.1093/her/ cyq024

[12] Ilies DC, Buhas R, Ilies A, et al. Indoor Air Quality Issue. Case Study: The Multipurpose Sports Hall of the University of Oradea. Environ Eng Management J. 2018;17(12);2999-3005. https://doi.org/10.30638/eemj.2018.300

[13] Sallis JF, Bowles HR, Bauman A, et al. Neighborhood environments and physical activity among adults in 11 countries. Am J Prevent Med. 2009;36(6):484-490. https://doi.org/10.1016/j.amepre.2009.01.031

[14] Bcsné Bába É, Fenyves V, Szabados G, Pető K, Bács Z, Dajnoki K. Sport Involvement Analysis in Hungary, in the North Great Plain Region. Sustainability. 2018; 10(5), 1629. DOI: 10.3390/su10051629. https://doi.org/10.3390/su10051629

[15] Pfau C, Domonkos Sz. Szabadidosport a felsooktatasban [Recreational sports in higher education]. TAYLOR. 2016;8(2):111-117. Hungarian.

[16] Pfau C. Hallgatoi szabadidosport szervezese es jellemzoi a felsooktatasban [Organizational and characteristics of student leisure sports in higher education]. TAYLOR. 2016;8(4):5-15. Hungarian.

[17] Kezar A. Organization theory and change. In Schuh JH, Jones SR, Torres V editors. Student Services: A Handbook for the Profession. 6th edition. San Francisco: Jossey-Bass; 2017, 220-235.

[18] Pfau C. Szabadidosport es a sportinfrastruktura osszehasonlito elemzese a kutato egyetemeken [Comparative analysis of recreational sports and sports infrastructure in research universities]. TAYLOR. 2014; 6(1-2):413-422. Hungarian. 